\title{
Brugada syndrome diagnosed from the EKG leads in the High Intercostal Spaces: Searching for Answers from a Higher Source?
}

Saurabh Kumar, BSc(Med)/MBBS, PhD ${ }^{1,2}$, Jonathan M. Kalman, MBBS, PhD²

${ }^{1}$ Arrythmia Service, Cardiovascular Division, Brigham \& Women’s Hospital, Harvard Medical School, Boston, MA, USA.

${ }^{2}$ Department of Cardiology, Division of Medicine, The Royal Melbourne Hospital and University of Melbourne, Melbourne, Australia.

Correspondence: Dr. Saurabh Kumar, Cardiovascular Division, Brigham \& Women’s Hospital, Harvard Medical School, Boston, MA, USA, 75 Francis St, Boston, MA, USA. Phone:

+18572059630; Fax: +18573071944; email: skumar15@partners.org or saurabh.kumar@mh.org.au.

Short title: "Kumar and Kalman: Brugada diagnosis from High Intercostal EKG Leads"

Word count: 3067

Disclosures: Dr. Kumar is a recipient of the Neil Hamilton Fairley Overseas Research scholarship cofunded by the National Health and Medical Research Council and the National Heart Foundation of Australia; and the Bushell Travelling Fellowship funded by the Royal Australasian College of Physicians.

Keywords: Brugada syndrome, electrocardiograph, risk stratification, sudden death. 
As is well known, Brugada syndrome is an autosomal dominant inherited disorder with variable expressivity that is characterized by ST-segment elevation in the right precordial leads and an increased risk of ventricular fibrillation and sudden cardiac death. ${ }^{1}$ Since the seminal report of this condition by Brugada and Brugada in $1992,{ }^{2}$ no other inherited arrhythmogenic disorder has perhaps generated more passionate debate than $\mathrm{BrS}$, with many controversies related to the underlying mechanism, methods of risk stratification, prognosis of its phenotypic manifestations and its long term management. ${ }^{1,3}$ Of paramount importance are two competing theories of the underlying mechanism of arrhythmogenesis. The depolarization hypothesis proposes that defective sodium channel function (leading to a weak inward sodium current during phase 1 of the action potential), in combination with a unopposed transient outward current $\left(\mathrm{I}_{t o}\right)$, which is most prominent in the right ventricular outflow tract (RVOT) epicardium leads to an accentuation of the action potential notch in the RV epicardium rather than the endocardium, resulting in an accentuated J wave and ST segment elevation characteristic of the Brugada pattern EKG. ${ }^{1}$ Arrhythmias are thought to develop because of inhomogeneous repolarization in different areas of the RV epicardium leading to phase 2 re-entry and to the development of closely coupled extrasystoles leading to ventricular arrhythmias. ${ }^{1}$ In contrast, recent evidence suggests that the RVOT epicardium in BrS harbors morphological and ultrastructural abnormalities not detectable by current imaging modalities, but demonstrable with electrophysiologic mapping, ${ }^{4-7}$ leading slow and discontinuous conduction that in turn conspire to produce an arrhythmogenic substrate, which may progress over time. ${ }^{8}$ Indeed, it is likely that a combination of the two mechanisms explains the arrhythmogenecity of BrS. ${ }^{9}$ Whilst the underlying mechanism is keenly 
debated, there is uniform agreement that it is the RVOT, which harbors the arrhythmogenic substrate in BrS.

To that end, the EKG remains the pivotal tool in establishing a diagnosis as leads V1 and V2, when placed in the standard position of the right and left fourth intercostal spaces (ICS) respectively, provide a vantage point for the detection of RV abnormalities. However, a number of prior studies have suggested that an EKG recorded from a high precordial location $\left(2^{\text {nd }}\right.$ or $3^{\text {rd }}$, rather than the $4^{\text {th }}$ ICS) may increase the sensitivity of diagnosis of BrS by providing an even more accurate vantage point, especially for the RVOT. ${ }^{10-17}$ Based on this rationale, the most recent expert consensus statement formally expanded the definition to include the Brugada EKG pattern with leads V1 and V2 positioned in the $2 \mathrm{nd}$, 3rd, or the 4th ICS, rather than standard lead placement in the $4^{\text {th }}$ ICS alone as diagnostic of BrS. ${ }^{18}$ This naturally creates a new category of patients in whom BrS EKG pattern is only evident by recordings from the high ICS. However there is limited data about the natural history and prognosis of such patients.

In this edition of the Journal, Curcio and colleagues, ${ }^{19}$ examined the role of high ICS lead placement in the diagnosis of BrS and the prognosis of such patients diagnosed exclusively by the high ICS. The authors report 300 patients in whom the diagnosis of BrS was not established using the former $2002^{20}$ or the $2005^{21}$ criteria (using standard EKG lead placement), both at baseline and after provocative testing with sodium-channel blocking agents. In these patients, $\mathrm{BrS}$ was suspected on the basis of history of syncope (21\% of patients), cardiac arrest (2.6\%), minor symptoms (40.7\%), or were asymptomatic (35.7\%). A family history of sudden cardiac death was present in $19 \%$ and a family history of BrS in 3\% of patients. No patients had evidence of structural heart disease. A 
large number high ICS EKGs without provocation (1819, with a median of 5 EKGs/patient) were systematically analyzed and the most severe EKG used for classification. Of the 300 patients, only 4 patients (1.3\%) had a spontaneous type I Brugada EKG detectable with high ICS placement, but not with standard placement. After provocative testing, a diagnostic type I Brugada EKG developed in the high ICS leads in a further 60 patients. Thus, 64 out of 300 were diagnosed with BrS using high ICS lead placement, either spontaneously or with provocative testing, amounting to a $21 \%$ increase in the yield of diagnosis. In follow up, only 3 of the 64 patients (4.7\%) developed cardiac events, that included two resuscitated cardiac arrests and one sudden cardiac death. These events occurred after a mean of $\sim 3$ years after initial clinical assessment. It is critical to note all 3 of these events occurred in patients in whom a spontaneous type I EKG pattern was evident in the high ICS space only. None of the patients with a drug-provoked type I EKG pattern in the high ICS developed cardiac events. The authors note that the 64 patients diagnosed using the high ICS space alone experienced a lifetime annual incidence of cardiac events of only $0.11 \%$ over a mean observation time of 41 years. The authors' surmise that this was truly a low risk group as the event rate in this "new" population was similar to patients diagnosed only after drug provocation using the 2002 criteria using standard ICS lead placement. Moreover, the event rate was significantly lower than patients with a spontaneous type I pattern diagnosed with standard lead positioning using the 2002 criteria, with or without a history of syncope.

The findings of Curcio et al., ${ }^{19}$ highlight the fundamental role of the EKG in dictating both, the diagnoses and prognosis of BrS. Whilst standard placement of V1 and 
V2 in the $4^{\text {th }}$ ICS place can diagnose BrS, a number of imaging and detailed mapping studies have shown that there are significant patient-specific differences in the electrical projection of the RVOT on chest surface. In an 87-electrode body surface mapping study, Shimizu et al ${ }^{10}$ showed that $28 \%$ of BrS patients had maximal ST segment elevation evident only in the $2^{\text {nd }}$ and $3^{\text {rd }}$ ICS whilst the $4^{\text {th }}$ ICS showed only mild saddleback ST segment elevation in such patients. Using right ventriculography, Nagase et $\mathrm{al}^{11}$ showed significant anatomic variation in the RVOT in relation to the $3^{\text {rd }}$ and $4^{\text {th }}$ ICS; indeed the RVOT overlay the $4^{\text {th }}$ ICS in only $18 \%$ and the 3rd ICS in $82 \%$ of patients. A type I EKG was recorded at the $4^{\text {th }}$ ICS in $82 \%$ of patients in whom the RVOT overlay the fourth ICS; however in $84 \%$ of patients in whom the RVOT overlay the $3{ }^{\text {rd }}$ ICS, a type I ECG was not seen at the $4^{\text {th }}$ ICS, but was seen at the 3rd ICS instead. Similarly, using cardiac MRI, Veltman et al ${ }^{17}$ showed that the RVOT was located over the $3^{\text {rd }}$ ICS in all patients in their cohort and that the location of the type I EKG highly correlated with the anatomic location of the RVOT. ${ }^{17}$ Savastano et al ${ }^{16}$ showed that a diagnostic Brugada ECG was present exclusively in the high ICS in $44 \%$ of patients in their cohort. In that study, echocardiographic guided EKG lead placement over the visualized RVOT markedly improved the diagnostic yield of BrS. Clearly, individual variation in location of the RVOT in relation to the intercostal space will critically influence whether the standard lead position will consistently capture the anatomic location of the RVOT. When coupled with the day-to-day variation in the typical type I BrS pattern, ${ }^{22}$ EKG lead placement directly overlying the RVOT, using imaging, if necessary will most likely play a future role in improving the diagnostic yield of BrS. Moreover, if the disease is heterogeneous in its mechanism ${ }^{1}$ (and possibly in its progression) ${ }^{8}$, it is plausible that a sub-population 
detectable only with high ICS lead placement representing “early” or a milder phenotype may emerge.

Prior studies, have also shown a $20-40 \%$ increase in the yield of detecting a Brugada EKG pattern, ${ }^{12-15}$ either spontaneously or with drug provocation, consistent with the $21 \%$ increase in yield reported by Curcio et al. ${ }^{19}$ In contrast to the benign prognosis of patients diagnosed exclusively on the basis of high ICS leads reported by Curcio et al., ${ }^{19}$ prior studies have reported that such patients face a similar incidence of adverse cardiac events when compared to patients diagnosed using the standard ICS leads. ${ }^{15,16}$ However, a valid comparison between these studies may not be plausible, as the populations studied were quite different. For example, the studies by Miyamoto et $\mathrm{al}^{15}$ and Savastano et $\mathrm{al}^{16}$ included a very high incidence of patients detected exclusively using the high ICS (28\% and $44 \%$ respectively compared with $21 \%$ in Curcio et $\mathrm{al}^{19}$ ); moreover, the proportion of symptomatic patients, the proportion of patients with spontaneous versus drug-provoked Brugada EKG pattern and the geographical location of the population also varied. Furthermore, prior studies were of smaller sample size and included patients with the Brugada EKG from both standard and high ICS lead placement, whilst Curcio et al, ${ }^{19}$ exclusively studied patients in whom a Brugada pattern was not seen using standard ICS lead placement. Importantly, none of the patients diagnosed with Brugada EKG exclusively on high ICS lead placement after drug provocation in the study by Curcio et al, ${ }^{19}$ experienced any cardiac events which was similar to the prognosis of patients who were diagnosed with drug provocation using standard ICS lead placement. This group is likely to represent a truly low risk group. ${ }^{3}$ However the prognosis of patients diagnosed exclusively with high ICS lead placement in the absence of drug provocation needs 
further study, as the numbers of such patients in the present study were small (4 patients) and the follow up duration was limited (36 months).

Predictions on diagnostic yield on high ICS and long-term prognosis are clearly influenced by the baseline incidence of BrS amongst different population. For example, the Type I ECG is observed more frequently in Asia (0-0.36\%) and Europe (0-0.25\%) than the USA ( $0.03 \%)$. Similarly, the type 2 or 3 ECG is also observed more frequently in Asia (0.12-2.23\%) and in Europe (0-0.6\%) than in the USA (0.02\%). ${ }^{1}$ Further study is therefore needed to determine the incidence of the Brugada type EKG from the high ICS amongst large, geographically diverse populations. Moreover, cardiac event rates may also vary according to the geographic population, warranting further definition. As this new population of patients emerge, there is no doubt questions will arise seeking clarification of the prognosis patients diagnosed exclusively with high ICS who experience syncope, and the prognostic role of electrophysiologic testing in such patients who are asymptomatic. Finally, the low diagnostic yield with genetic testing (positive in $20-30 \%$ of BrS patients) also means that there is an absence of a gold standard by which conclusions about diagnostic yield can be accurately judged. As this was a retrospective study, larger prospective and multi-center studies are needed to clarify the prognosis of patients with a Brugada EKG pattern diagnoses exclusively by high ICS lead placement.

The study by Curcio et al. ${ }^{19}$ is not only systematic but is also timely, insightful and sourced from a highly experienced center with a fine legacy of seminal observations in inherited arrhythmogenic disorders. The study sheds light onto a rapidly emerging group of patients who will be reclassified with BrS or a Brugada-like EKG, and are now formally recognized by the guidelines. ${ }^{18}$ The study provides great impetus in further 
characterizing the prognosis of such patients. It also confirms the pivotal role of the EKG in diagnosis and risk stratification and suggests that further work is needed to refine lead placement to match RVOT position to improve the diagnostic accuracy of the EKG in detected BrS. 


\section{$\underline{\text { Author contributions }}$}

Dr. Saurabh Kumar: Drafting article; critical revision of the article.

Dr. Jonathan Kalman: Critical revision of the article. 


\section{$\underline{\text { References }}$}

1. Mizusawa Y, Wilde AA: Brugada syndrome. Circ Arrhythm Electrophysiol 2012; 5:606-616.

2. Brugada P, Brugada J: Right bundle branch block, persistent ST segment elevation and sudden cardiac death: a distinct clinical and electrocardiographic syndrome. A multicenter report. J Am Coll Cardiol 1992; 20:1391-1396.

3. Adler A, Rosso R, Chorin E, Havakuk O, Antzelevitch C and Viskin S: Risk stratification in Brugada syndrome: Clinical characteristics, electrocardiographic parameters, and auxiliary testing. Heart Rhythm 2016; 13:299-310.

4. Nademanee K, Raju H, de Noronha SV, Papadakis M, Robinson L, Rothery S, Makita N, Kowase S, Boonmee N, Vitayakritsirikul V, Ratanarapee S, Sharma S, van der Wal AC, Christiansen M, Tan HL, Wilde AA, Nogami A, Sheppard MN, Veerakul G and Behr ER: Fibrosis, Connexin-43, and Conduction Abnormalities in the Brugada Syndrome. J Am Coll Cardiol 2015; 66:1976-1986.

5. Lambiase PD, Ahmed AK, Ciaccio EJ, Brugada R, Lizotte E, Chaubey S, BenSimon R, Chow AW, Lowe MD and McKenna WJ: High-density substrate mapping in Brugada syndrome: combined role of conduction and repolarization heterogeneities in arrhythmogenesis. Circulation 2009; 120:106-117, 101-104.

6. Postema PG, van Dessel PF, de Bakker JM, Dekker LR, Linnenbank AC, Hoogendijk MG, Coronel R, Tijssen JG, Wilde AA and Tan HL: Slow and discontinuous conduction conspire in Brugada syndrome: a right ventricular mapping and stimulation study. Circ Arrhythm Electrophysiol 2008; 1:379-386. 
7. Ten Sande JN, Coronel R, Conrath CE, Driessen AH, de Groot JR, Tan HL, Nademanee K, Wilde AA, de Bakker JM and van Dessel PF: ST-Segment Elevation and Fractionated Electrograms in Brugada Syndrome Patients Arise From the Same Structurally Abnormal Subepicardial RVOT Area but Have a Different Mechanism. Circ Arrhythm Electrophysiol 2015; 8:1382-1392.

8. Notarstefano P, Pieroni M, Guida R, Rio T, Oliva A, Grotti S, Fraticelli A and Bolognese L: Progression of electroanatomic substrate and electric storm recurrence in a patient with Brugada syndrome. Circulation 2015; 131:838-841.

9. Zhang J, Sacher F, Hoffmayer K, O'Hara T, Strom M, Cuculich P, Silva J, Cooper D, Faddis M, Hocini M, Haissaguerre M, Scheinman M and Rudy Y: Cardiac electrophysiological substrate underlying the ECG phenotype and electrogram abnormalities in Brugada syndrome patients. Circulation 2015; 131:1950-1959.

10. Shimizu W, Matsuo K, Takagi M, Tanabe Y, Aiba T, Taguchi A, Suyama K, Kurita T, Aihara N and Kamakura S: Body surface distribution and response to drugs of ST segment elevation in Brugada syndrome: clinical implication of eighty-seven-lead body surface potential mapping and its application to twelve-lead electrocardiograms. J Cardiovasc Electrophysiol 2000; 11:396-404.

11. Nagase S, Hiramatsu S, Morita H, Nishii N, Murakami M, Nakamura K, Kusano $\mathrm{KF}$, Ito $\mathrm{H}$ and Ohe $\mathrm{T}$ : Electroanatomical correlation of repolarization abnormalities in Brugada syndrome: detection of type 1 electrocardiogram in the right ventricular outflow tract. J Am Coll Cardiol 2010; 56:2143-2145.

12. Govindan M, Batchvarov VN, Raju H, Shanmugam N, Bizrah M, Bastiaenen R, Kiotsekoglou A, Camm J and Behr ER: Utility of high and standard right precordial leads 
during ajmaline testing for the diagnosis of Brugada syndrome. Heart 2010; 96:19041908.

13. Sangwatanaroj S, Prechawat S, Sunsaneewitayakul B, Sitthisook S, Tosukhowong P and Tungsanga K: New electrocardiographic leads and the procainamide test for the detection of the Brugada sign in sudden unexplained death syndrome survivors and their relatives. Eur Heart J 2001; 22:2290-2296.

14. Shimeno K, Takagi M, Maeda K, Tatsumi H, Doi A and Yoshiyama M: Usefulness of multichannel Holter ECG recording in the third intercostal space for detecting type 1 Brugada ECG: comparison with repeated 12-lead ECGs. J Cardiovasc Electrophysiol 2009; 20:1026-1031.

15. Miyamoto K, Yokokawa M, Tanaka K, Nagai T, Okamura H, Noda T, Satomi K, Suyama K, Kurita T, Aihara N, Kamakura S and Shimizu W: Diagnostic and prognostic value of a type 1 Brugada electrocardiogram at higher (third or second) V1 to V2 recording in men with Brugada syndrome. Am J Cardiol 2007; 99:53-57.

16. Savastano S, Rordorf R, Vicentini A, Petracci B, Taravelli E, Castelletti S, D'Errico A, Torchio M, Dossena C, Novara P, Dagradi F, Landolina M, Spazzolini C, Crotti L and Schwartz PJ: A comprehensive electrocardiographic, molecular, and echocardiographic study of Brugada syndrome: validation of the 2013 diagnostic criteria. Heart Rhythm 2014; 11:1176-1183.

17. Veltmann C, Papavassiliu T, Konrad T, Doesch C, Kuschyk J, Streitner F, Haghi D, Michaely HJ, Schoenberg SO, Borggrefe M, Wolpert C and Schimpf R: Insights into the location of type I ECG in patients with Brugada syndrome: correlation of ECG and cardiovascular magnetic resonance imaging. Heart Rhythm 2012; 9:414-421. 
18. Priori SG, Wilde AA, Horie M, Cho Y, Behr ER, Berul C, Blom N, Brugada J, Chiang CE, Huikuri H, Kannankeril P, Krahn A, Leenhardt A, Moss A, Schwartz PJ, Shimizu W, Tomaselli G and Tracy C: HRS/EHRA/APHRS expert consensus statement on the diagnosis and management of patients with inherited primary arrhythmia syndromes: document endorsed by HRS, EHRA, and APHRS in May 2013 and by ACCF, AHA, PACES, and AEPC in June 2013. Heart Rhythm 2013; 10:1932-1963.

19. Curcio A, Mazzanti A, Bloise R, Monteforte N, Indolfi C, Priori SG and Napolitano C: Clinical presentation and outcome of Brugada syndrome diagnosed with the new 2013 criteria. J Cardiovasc Electrophysiol 2016 Apr 21. doi: 10.1111/jce.12997. [Epub ahead of print]

20. Wilde AA, Antzelevitch C, Borggrefe M, Brugada J, Brugada R, Brugada P, Corrado D, Hauer RN, Kass RS, Nademanee K, Priori SG, Towbin JA and Study Group on the Molecular Basis of Arrhythmias of the European Society of C: Proposed diagnostic criteria for the Brugada syndrome: consensus report. Circulation 2002; 106:2514-2519.

21. Antzelevitch C, Brugada P, Borggrefe M, Brugada J, Brugada R, Corrado D, Gussak I, LeMarec H, Nademanee K, Perez Riera AR, Shimizu W, Schulze-Bahr E, Tan H and Wilde A: Brugada syndrome: report of the second consensus conference: endorsed by the Heart Rhythm Society and the European Heart Rhythm Association. Circulation 2005; 111:659-670.

22. Matsuo K, Shimizu W, Kurita T, Inagaki M, Aihara N and Kamakura S: Dynamic changes of 12-lead electrocardiograms in a patient with Brugada syndrome. J Cardiovasc Electrophysiol 1998; 9:508-512. 


\section{University Library}

\section{- M M N E R VA A gateway to Melbourne's research publications}

Minerva Access is the Institutional Repository of The University of Melbourne

Author/s:

Kumar, S;Kalman, JM

Title:

Brugada Syndrome Diagnosed from the ECG Leads in the High Intercostal Spaces:

Searching for Answers from a Higher Source?

Date:

2016-08-01

Citation:

Kumar, S. \& Kalman, J. M. (2016). Brugada Syndrome Diagnosed from the ECG Leads in the High Intercostal Spaces: Searching for Answers from a Higher Source?. JOURNAL OF CARDIOVASCULAR ELECTROPHYSIOLOGY, 27 (8), pp.944-946. https://doi.org/10.1111/ jce.13016.

Persistent Link:

http://hdl.handle.net/11343/127430 